NASA/TM-2000-208876

\title{
Correlation Between Material Properties of Ferroelectric Thin Films and Design Parameters for Microwave Device Applications: Modeling Examples and Experimental Verification
}

Félix A. Miranda and Fred W. Van Keuls

Glenn Research Center, Cleveland, Ohio

Guru Subramanyam

University of Dayton, Dayton, Ohio

Carl H. Mueller and Robert R. Romanofsky

Glenn Research Center, Cleveland, Ohio

Gerardo Rosado

University of Puerto Rico, Humacao, Puerto Rico 
Since its founding, NASA has been dedicated to the advancement of aeronautics and space science. The NASA Scientific and Technical Information (STI) Program Office plays a key part in helping NASA maintain this important role.

The NASA STI Program Office is operated by Langley Research Center, the Lead Center for NASA's scientific and technical information. The NASA STI Program Office provides access to the NASA STI Database, the largest collection of aeronautical and space science STI in the world. The Program Office is also NASA's institutional mechanism for disseminating the results of its research and development activities. These results are published by NASA in the NASA STI Report Series, which includes the following report types:

- TECHNICAL PUBLICATION. Reports of completed research or a major significant phase of research that present the results of NASA programs and include extensive data or theoretical analysis. Includes compilations of significant scientific and technical data and information deemed to be of continuing reference value. NASA's counterpart of peerreviewed formal professional papers but has less stringent limitations on manuscript length and extent of graphic presentations.

- TECHNICAL MEMORANDUM. Scientific and technical findings that are preliminary or of specialized interest, e.g., quick release reports, working papers, and bibliographies that contain minimal annotation. Does not contain extensive analysis.

- CONTRACTOR REPORT. Scientific and technical findings by NASA-sponsored contractors and grantees.
- CONFERENCE PUBLICATION. Collected papers from scientific and technical conferences, symposia, seminars, or other meetings sponsored or cosponsored by NASA.

- SPECIAL PUBLICATION. Scientific, technical, or historical information from NASA programs, projects, and missions, often concerned with subjects having substantial public interest.

- TECHNICAL TRANSLATION. Englishlanguage translations of foreign scientific and technical material pertinent to NASA's mission.

Specialized services that complement the STI Program Office's diverse offerings include creating custom thesauri, building customized data bases, organizing and publishing research results ... . even providing videos.

For more information about the NASA STI Program Office, see the following:

- Access the NASA STI Program Home Page at http://www.sti.nasa.gov

- E-mail your question via the Internet to help@sti.nasa.gov

- Fax your question to the NASA Access Help Desk at (301) 621-0134

- Telephone the NASA Access Help Desk at (301) 621-0390

- Write to: NASA Access Help Desk NASA Center for AeroSpace Information 7121 Standard Drive

Hanover, MD 21076 
NASA/TM-2000-208876

\section{Correlation Between Material Properties of Ferroelectric Thin Films and Design Parameters for Microwave Device Applications: Modeling Examples and Experimental Verification}

Félix A. Miranda and Fred W. Van Keuls

Glenn Research Center, Cleveland, Ohio

Guru Subramanyam

University of Dayton, Dayton, Ohio

Carl H. Mueller and Robert R. Romanofsky

Glenn Research Center, Cleveland, Ohio

Gerardo Rosado

University of Puerto Rico, Humacao, Puerto Rico

Prepared for the

11th International Symposium on Integrated Ferroelectrics

cosponsored by the Gordon and Breach Science Publishers and

the University of Colorado

Colorado Springs, Colorado, March 7-10, 1999

National Aeronautics and

Space Administration

Glenn Research Center 
Trade names or manufacturers' names are used in this report for identification only. This usage does not constitute an official endorsement, either expressed or implied, by the National Aeronautics and Space Administration.

Available from

NASA Center for Aerospace Information 7121 Standard Drive

Hanover, MD 21076

Price Code: A03
National Technical Information Service 5285 Port Royal Road Springfield, VA 22100

Price Code: A03 


\title{
CORRELATION BETWEEN MATERIAL PROPERTIES OF FERROELECTRIC THIN FILMS AND DESIGN PARAMETERS FOR MICROWAVE DEVICE APPLICATIONS: MODELING EXAMPLES AND EXPERIMENTAL VERIFICATION
}

\author{
Félix A. Miranda and Fred W. Van Keuls \\ Glenn Research Center \\ Cleveland, Ohio 44135 \\ Guru Subramanyam \\ University of Dayton \\ Dayton, Ohio 45469 \\ Carl H. Mueller and Robert R. Romanofsky \\ Glenn Research Center \\ Cleveland, Ohio 44135 \\ Gerardo Rosado \\ University of Puerto Rico, \\ Humacao, Puerto Rico 00791
}

The application of thin ferroelectric films for frequency and phase agile components is the topic of interest of many research groups worldwide. Consequently, proof-of-concepts (POC) of different tunable microwave components using either (HTS, metal)/ferroelectric thin film/dielectric heterostructures or (thick, thin) film "flip-chip" technology have been reported. Either as ferroelectric thin film characterization tools or from the point of view of circuit implementation approach, both configurations have their respective advantages and limitations. However, we believe that because of the progress made so far using the heterostructure (i.e., multilayer) approach, and due to its intrinsic features such as planar configuration and monolithic integration, a study on the correlation of circuit geometry aspects and ferroelectric material properties could 
accelerate the insertion of this technology into working systems. In this paper, we will discuss our study performed on circuits based on microstrip lines at frequencies above $10 \mathrm{GHz}$, where the multilayer configuration offers greater ease of insertion due to circuit's size reduction. Modeled results of relevant circuit parameters such as the characteristic impedance, effective dielectric constant, and attenuation as a function of ferroelectric film's dielectric constant, $\tan \delta$, and thickness, will be presented for $\mathrm{SrTiO}_{3}$ and $\mathrm{Ba}_{\mathrm{x}} \mathrm{Sr}_{1-\mathrm{x}} \mathrm{TiO}_{3}$ ferroelectric films. A comparison between the modeled and experimental data for some of these parameters will be presented.

\section{INTRODUCTION}

The prospects of using ferroelectric thin films for the fabrication and development of frequency and phase agile microwave circuits have increased in recent years due to improvements in film deposition and processing techniques, as well as innovative circuit designs. For example, thin films of $\mathrm{SrTiO}_{3}$, henceforth STO, deposited by laser ablation have shown relative dielectric constant $\left(\varepsilon_{\mathrm{r}}\right)$ ranging from 5000 to 300 , at zero bias and $9 \times 10^{4} \mathrm{~V} / \mathrm{cm}$, respectively, at $5 \mathrm{GHz}$, and $77 \mathrm{~K} .{ }^{[1]}$ Likewise, films of $\mathrm{Ba}_{\mathrm{x}} \mathrm{Sr}_{1-\mathrm{x}} \mathrm{TiO}_{3}(\mathrm{Ba}: \mathrm{Sr} ; 60: 40)$, henceforth BSTO, have been deposited using laser ablation and exhibit $\varepsilon_{\mathrm{r}} \sim 730-310$ (undoped) and $\varepsilon_{\mathrm{r}} \sim 1820-800$ ( $1 \% \mathrm{Mn}$-doped) at $10 \mathrm{GHz}$ and $300 \mathrm{~K}$, at zero applied field and $5 \times 10^{4} \mathrm{~V} / \mathrm{cm}$, respectively. ${ }^{[2]}$ Reported $\tan \delta$ values for STO films are within the 0.05 to 0.001 range, while values of 0.040 and 0.017 (undoped) and 0.006 and 0.002 ( $1 \% \mathrm{Mn}$ doped) have been measured for BSTO at no field and $5 \times 10^{4} \mathrm{~V} / \mathrm{cm}$, respectively.

In the area of applications, proof-of-concept (POC) of microwave components such as tunable resonators, filters, local oscillators, and phase shifters have been already demonstrated at $\mathrm{Ku}$-and $\mathrm{K}$-band frequencies. ${ }^{[2-6]}$ Despite their prototypical nature, the performance of these devices has been comparable, and in some occasions superior, to those of their conventional technology counterparts.

Relevant to the rapid insertion of this technology into working microwave systems, ought to be the realization that specific applications demand particular characteristics (i.e., nonuniversal features) regarding the material properties of the ferroelectric films, the circuit design, and the application of the external dc field. For example, Synowczynski, et al., ${ }^{[7]}$ 
and Van Keuls, et al., ${ }^{[3]}$ have shown that there exists different material, circuit, and biasing requirements for a circuit intended for small tuning but high Q (i.e., small losses) as compared to those intended for broad tuning and high $Q$, etc. There are also different material specifications depending on the temperature range of operation of a given component. For low temperature applications it is advantageous to use STO since one can exploit its low temperature tunability with the added benefit of low electrical loss by using high temperature superconducting (HTS) thin film as the conducting electrodes. ${ }^{[8]}$ On the other hand, using BSTO for applications near room temperature is more convenient since its material properties can be tailored to show large tunabilities at this temperature.

In this paper, we will discuss modeled results of relevant circuit parameters such as the characteristic impedance $\left(Z_{0}\right)$, effective dielectric constant $\left(\varepsilon_{\text {eff }}\right)$, and attenuation $\left(I_{L}\right)$ as a function of circuit geometry (i.e., transmission line width (W), spacing between the top conductor and ground plane $(\mathrm{H})$ ) and ferroelectric film's properties such as relative dielectric constant $\left(\varepsilon_{\mathrm{r}}\right)$, loss tangent $(\tan \delta)$, and thickness $(\mathrm{t})$. The modeled data will be based on $\mathrm{SrTiO}_{3}$ and $\mathrm{Ba}_{\mathrm{x}} \mathrm{Sr}_{1-\mathrm{x}} \mathrm{TiO}_{3}$ ferroelectric films. The level of correlation between modeled and experimental data will be discussed for some specific circuits.

\section{DESIGN AND MODELING}

This paper deals with the microstrip transmission line configuration. On one hand, this type of transmission line is rather ubiquitous in almost all the aforementioned devices. On the other, the number of parameters to be correlated within the context of the microstrip transmission line is large enough, preventing consideration of other types of transmission lines such as a stripline or a coplanar waveguide (CPW) in the same paper. Both stripline and CPW will be dealt with in a future study. In this effort our objective was to study the trade-offs between attaining tunability and the effects that a ferroelectric layer embedded between the dielectric substrate and the microstrip line would have upon the overall transmission line heterostructure. These effects will be evaluated in terms of the changes in the following critical design parameters for the tunable circuits: (1) Characteristic impedance and effective dielectric constant of the microstrip, (2) Electric field dependent tunable range of $\varepsilon_{\mathrm{r}}$ and $\tan \delta$ of the ferroelectric thin film, and (3) biasing method (e.g., unipolar and bipolar). 
The cross section of the multilayered microstrip structure modeled is shown in Fig. 1. The multilayered microstrip structure consists of a LAO dielectric substrate, typically $254 \mu \mathrm{m}$ thick, a ferroelectric thin film layer (its thickness varying from 300 to $2000 \mathrm{~nm}$ for various applications), a gold or HTS thin film ( $2 \mu \mathrm{m}$ thick or $350 \mathrm{~nm}$ thick, respectively) for the top conductor, and a $2 \mu \mathrm{m}$ thick gold ground plane. Important geometrical dimensions controlling the microstrip parameters are the width-toheight ratio $(\mathrm{W} / \mathrm{H})$, thickness of the ferroelectric film ( $\mathrm{t})$, and the thickness of the substrate (h); these dimensions are indicated in Fig. 1. The geometry of the multilayered microstrip was simulated using Sonnet em ${ }^{\circledR}$ and the Zeland's IE3D software ${ }^{[9]}$ to model the behavior of $Z_{\mathrm{o}}, \varepsilon_{\text {eff }}$, and $\mathrm{I}_{\mathrm{L}}$ as a function of frequency, $\mathrm{W} / \mathrm{H}$, and ferroelectric thin film's parameters such as $t, \varepsilon_{\mathrm{r}}$, and $\tan \delta$. Modeling was performed for microstrip lines with $\mathrm{Z}_{\mathrm{o}}$ 's of 25,50 , and $75 \Omega$, as determined in the absence of a ferroelectric film. The tunable range of $\varepsilon_{\mathrm{rFE}}$ was chosen to be between 5000 at zero-field to 300 at high field and $77 \mathrm{~K}$ for the STO film, and 2000 at zero-field to 500 at high field at room temperature for the BSTO thin film based on the data obtained from low frequency capacitance measurements on test structures. ${ }^{[1,2,}$ and 5$]$ It is important to mention that spatial variations of the relative dielectric constant of the ferroelectric film $\left(\varepsilon_{\mathrm{rFE}}\right)$ are neglected in our modeling. The $\varepsilon_{\mathrm{rFE}}$ varies spatially, going from fully biased under the microstrip to unbiased far away from the microstrip line, for a single microstrip. The variation is more complicated in a coupled microstrip, coupled ring resonator, filter or other more complex structure. Also, all of the circuits were modeled with a ferroelectric thin film layer present throughout the sample.

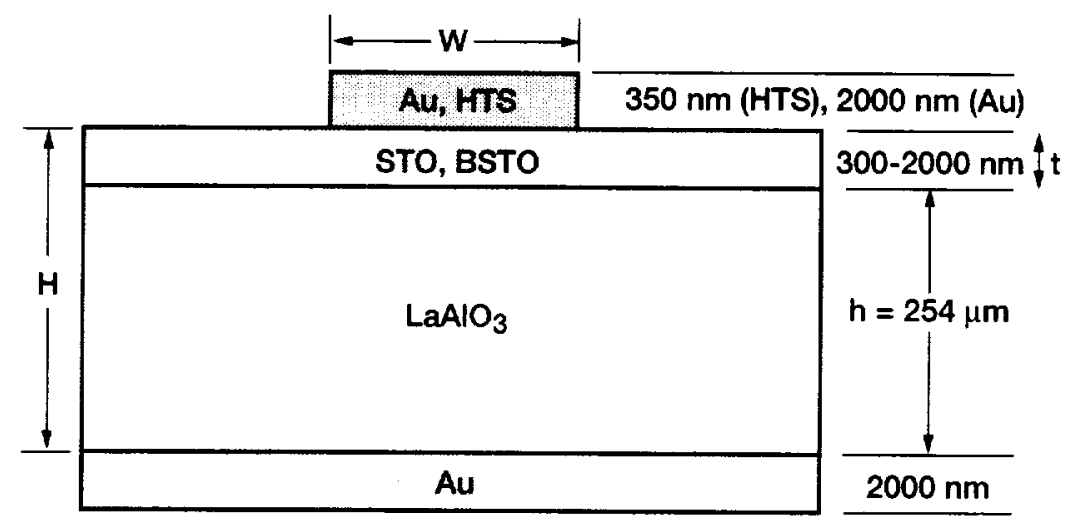

FIGURE 1 Schematic of a conductor/ferroelectric/dielectric microstrip line configuration. 


\section{EXPERIMENTAL}

The fabrication and testing of the tunable microwave devices have been discussed elsewhere. ${ }^{[3-6]}$ Briefly, the ferroelectric films considered here have been deposited by laser ablation on $254 \mu \mathrm{m}$ thick lanthanum aluminate $\left(\mathrm{LaAlO}_{3}\right)$ and have thicknesses within the 0.3 to $2.0 \mu \mathrm{m}$ range. The gold $(\mathrm{Au})$ metallization was done using electron beam evaporation. The microwave testing of the devices was performed under a vacuum of less than $1 \mathrm{mTorr}$, with the samples mounted on the cold finger of a helium gas closed-cycle refrigerator via a custom made test fixture. The microwave characterization was performed using an HP-8510-C Automatic Network Analyzer to measure the reflection and transmission scattering parameters $\left(S_{11}\right.$ and $S_{21}$, respectively). Application of dc voltages to the microstrip transmission lines was achieved through the SMA launchers using custom made bias tees designed to withstand up to $500 \mathrm{~V}$ dc at K-band frequencies. ${ }^{[10]}$

\section{RESULTS}

\section{A. Modeled Results:}

Our study was based on microstrip lines deposited on $\mathrm{LaAlO}_{3}$ (LAO) substrates $254 \mu \mathrm{m}$ thick. The first step in a microstrip circuit design is to determine the $\mathrm{W} / \mathrm{H}$ ratio required for a chosen characteristic impedance. Figure 2 shows $Z_{o}$ versus $\mathrm{W} / \mathrm{H}$ characteristics applicable to $\mathrm{K}$-band microstrip circuit design on LAO substrates, in the absence of a ferroelectric tuning layer. For $Z_{o}=25,50,75 \Omega$, the required $W / H$ values are $1.63,0.345$, and 0.08 , respectively. When a ferroelectric thin film layer is inserted, as shown in Fig. 1, the effective dielectric constant ( $\left.\varepsilon_{\text {eff }}\right)$ of the structure and the characteristic impedance $\left(\mathrm{Z}_{\mathrm{o}}\right)$ of the microstrip are tunable between a minimum and a maximum value for each due to the bias dependent change in the $\varepsilon_{\mathrm{rFE}}$. The change in $\mathrm{Z}_{\mathrm{o}}$ and $\varepsilon_{\text {eff }}$ of microstrips corresponding to 25,50 , and $75 \Omega$ were plotted within the tunable range of the $\varepsilon_{\mathrm{rFE}}$, for a fixed thickness of the ferroelectric film and a fixed frequency of interest in the K-band. Figures 3 to 6 show the variations of $Z_{\mathrm{o}}$ and $\varepsilon_{\text {eff }}$ at $20 \mathrm{GHz}$ for $\mathrm{W} / \mathrm{H}=0.345$ and $\mathrm{W} / \mathrm{H}=1.63$ (i.e.. $\mathrm{Z}_{\mathrm{o}}=50$ and $Z_{o}=25 \Omega$, respectively) and three different thicknesses of the ferroelectric tuning layer. As is evident from these figures, the tunability in $Z_{0}$ and $\varepsilon_{\text {eff }}$ are higher for the smaller W/H, i.e., higher characteristic impedance. 


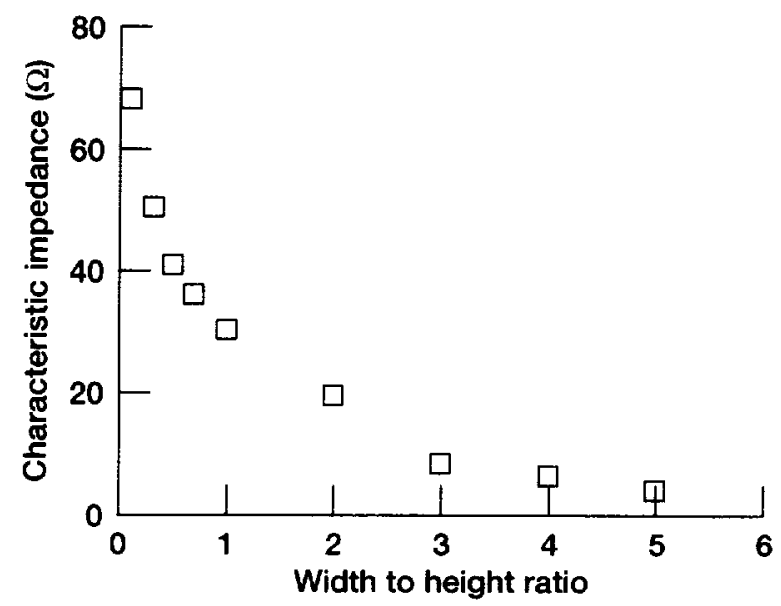

FIGURE 2 Modeled data of characteristic impedance $\left(Z_{0}\right)$ versus $\mathrm{W} / \mathrm{H}$ for a Au/STO/LAO microstrip line at $10 \mathrm{GHz}$.

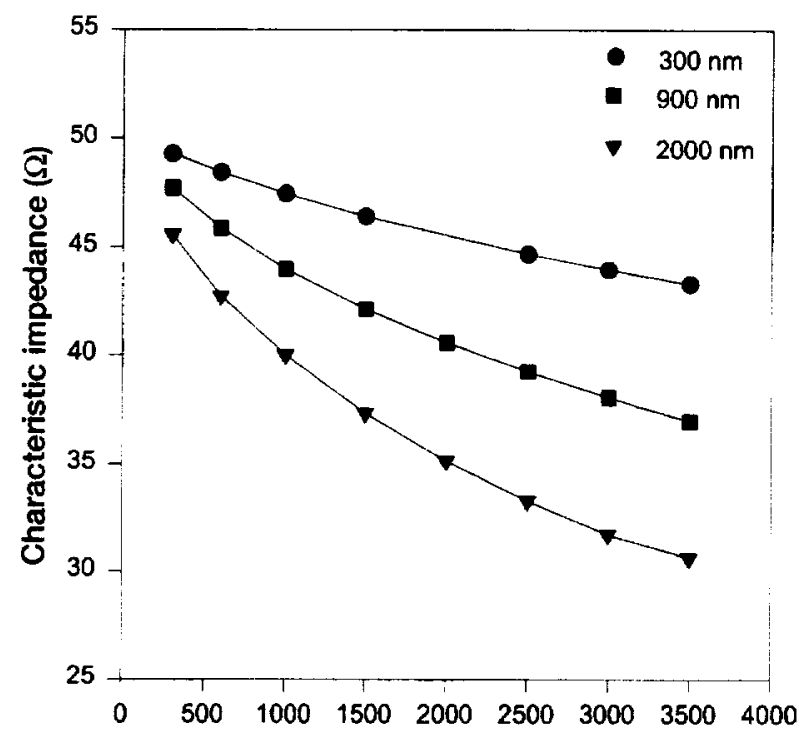

Relative dielectric constant of the ferroelectric film

FIGURE 3 Modeled data for characteristic impedance $\left(Z_{0}\right)$ of a $50 \Omega$ line versus the relative dielectric constant of the ferroelectric film $\left(\varepsilon_{\mathrm{rFE}}\right)$ for three different thicknesses of the ferroelectric film at $20 \mathrm{GHz}$ and $\tan \delta=0.01$. 


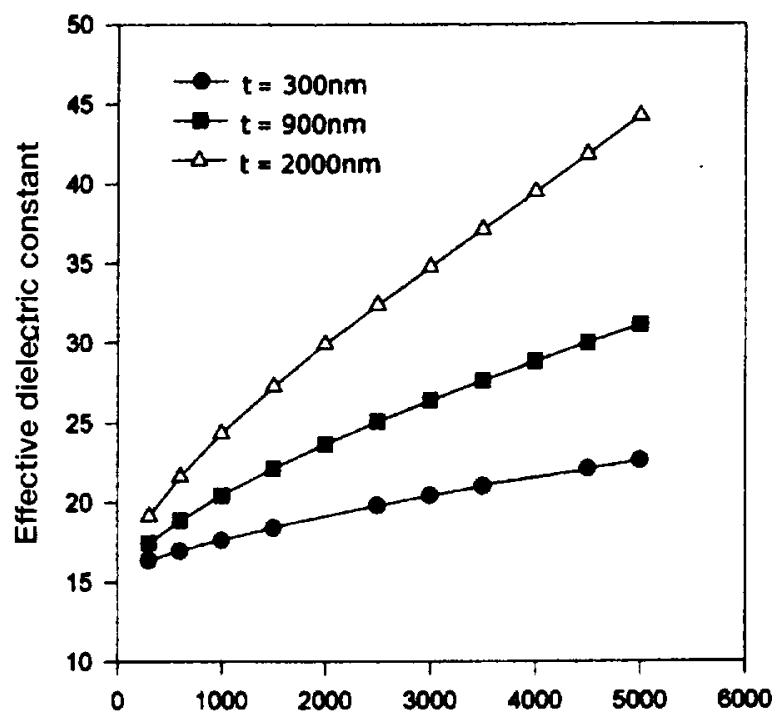

Relative dielectric constant of the ferroelectric film

FIGURE 4 Modeled data for effective dielectric constant $\left(\varepsilon_{\text {efft }}\right)$ of a $50 \Omega$ line versus relative dielectric constant of the ferroelectric film $\left(\varepsilon_{\mathrm{rFE}}\right)$ for three different thicknesses of the ferroelectric film at $20 \mathrm{GHz}$ and $\tan \delta=0.01$.

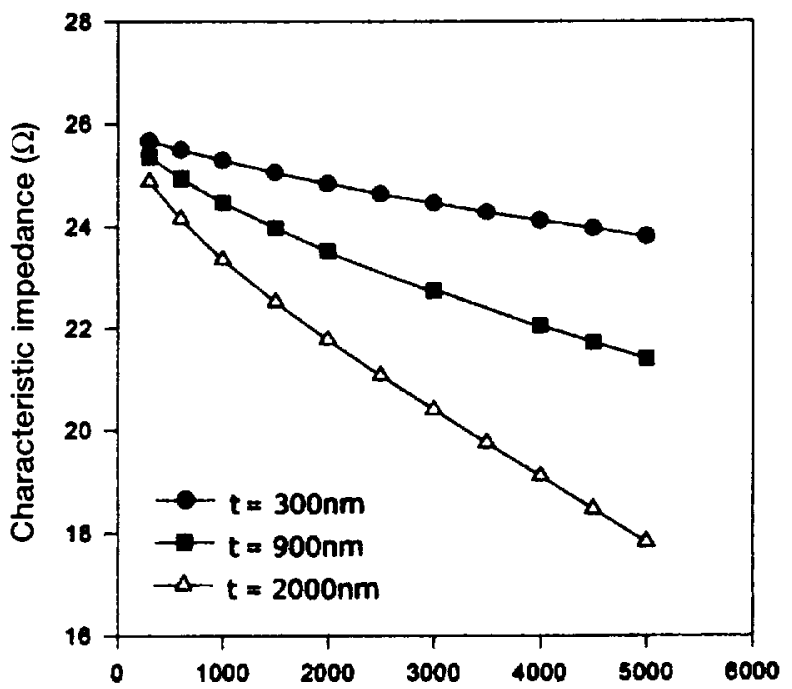

Relative dielectric constant of the ferroelectric film

FIGURE 5 Modeled data for characteristic impedance $\left(Z_{0}\right)$ of a $25 \Omega$ line versus the relative dielectric constant of the ferroelectric film ( $\left.\varepsilon_{\mathrm{rFE}}\right)$ for three different thicknesses of the ferroelectric film at $20 \mathrm{GHz}$ and $\tan \delta=0.01$. 


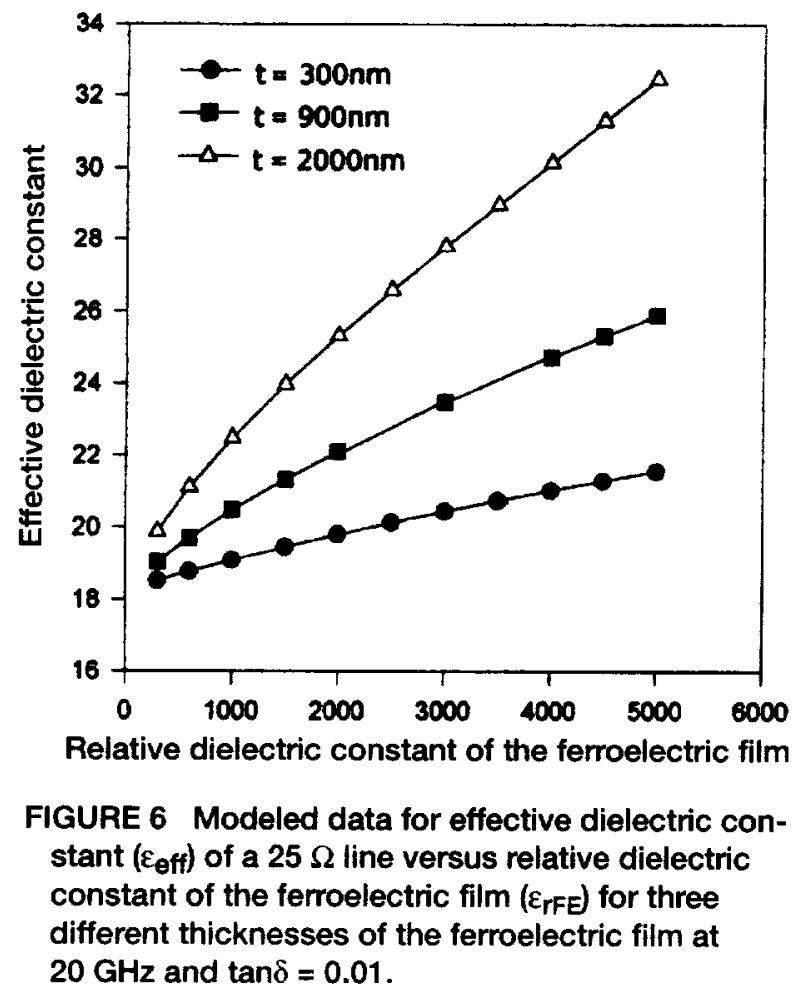

Percentage change in $Z_{o}$ and $\varepsilon_{\text {eff }}$ is higher for the $50 \Omega$ compared to the $25 \Omega$ microstripline, however it is the highest for the $75 \Omega$ microstrip line. Table I summarizes these results for $20 \mathrm{GHz}$.

This trend prevails also at frequencies of 10 and $15 \mathrm{GHz}$. This is an important result, as one can choose higher characteristic impedance for obtaining larger frequency tunability since it is directly related to the percentage change in $Z_{o}$ and $\varepsilon_{\text {eff. }}$

From Figs. 5, 7 and 8, one can see that $Z_{o}$ increases with increasing frequency and decreases with film thickness; this was observed for all the $\mathrm{W} / \mathrm{H}$ values. The high dielectric constant of the ferroelectric film with respect to that of the $\operatorname{LAO}\left(\varepsilon_{\mathrm{r}} \sim 24\right)$ introduce the deviation in $Z_{\mathrm{o}}$. Obviously, this effect becomes more prominent as the thickness of the STO increases. This trend is only dependent on the real part of the permittivity, which explains the fact that for a given frequency, $Z_{0}$ versus ${ }^{t}{ }_{\text {STO }}$ was the same for $\tan \delta$ values of $0.1,0.01$, and 0.005 . The behavior of $\varepsilon_{\text {eff }}$ is also consistent with the skin depth effect as it increases as a function of frequency and film thickness. Also as expected it is independent of the value of $\tan \delta$. 
TABLE I Modeled percentage change in $Z_{0}$ and $\varepsilon_{\text {eff }}$ for 25,50 , and $75 \Omega$ microstrip lines versus $\varepsilon_{\mathrm{rFF}}$ at $20 \mathrm{GHz}$ for three different thicknesses of the ferroelectric film; $\tan \delta=0.01$

\begin{tabular}{|c|c|c|c|c|c|c|}
\hline \multirow{2}{*}{$\begin{array}{c}\text { Thickness of } \\
\text { FE film, } \\
\text { nm }\end{array}$} & \multicolumn{2}{|c|}{$25 \Omega 25 \Omega$} & $50 \Omega$ & $50 \Omega$ & $75 \Omega$ & $75 \Omega$ \\
\hline & $\mathrm{Z}_{\mathrm{o}}$ & $\varepsilon_{\mathrm{eff}}$ & $\overline{Z_{0}}$ & $\varepsilon_{\mathrm{eff}}$ & $Z_{\mathrm{o}}$ & $\varepsilon_{\mathrm{eff}}$ \\
\hline 300 & 5 & 10 & 11 & 26 & 17 & 46 \\
\hline 900 & 10 & 23 & 19 & 54 & 26 & 82 \\
\hline 2000 & 18 & 40 & 27 & 87 & 33 & 124 \\
\hline $\begin{array}{l}\% \text { change } Z_{o}= \\
300)) /\left(Z_{o} \text { fo }\right. \\
\% \text { change } \varepsilon_{\text {eff }}= \\
300)) /\left(\varepsilon_{\text {eff }}\right.\end{array}$ & $\begin{array}{l}{\left[\left(\left(Z_{\mathrm{o}}\right.\right.\right.} \\
r \varepsilon_{\mathrm{rFE}} \\
{\left[\left(\left(\varepsilon_{\mathrm{ef}}\right.\right.\right.}\end{array}$ & $\varepsilon_{\mathrm{rF}}$ & $\begin{array}{l}3000 \\
00 . \\
=3000 \\
00\end{array}$ & Zo & $\mathrm{FE}=$ & \\
\hline
\end{tabular}

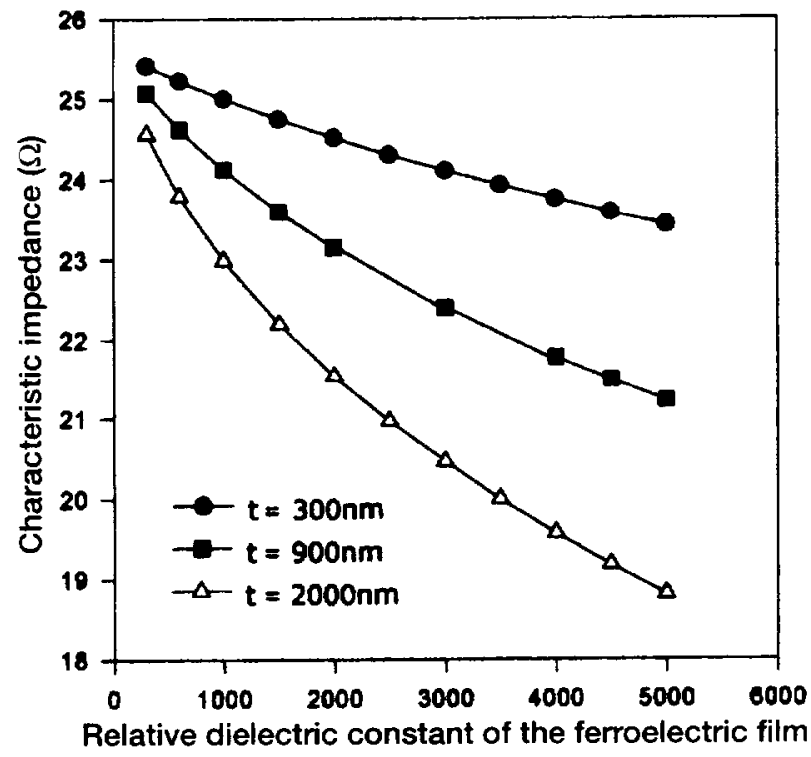

FIGURE 7 Modeled data for characteristic impedance $\left(Z_{0}\right)$ of a $25 \Omega$ line versus the relative dielectric constant of the ferroelectric film $\left(\varepsilon_{\mathrm{rFE}}\right)$ for three different thicknesses of the ferroelectric film at $10 \mathrm{GHz}$ and $\tan \delta=0.01$. 


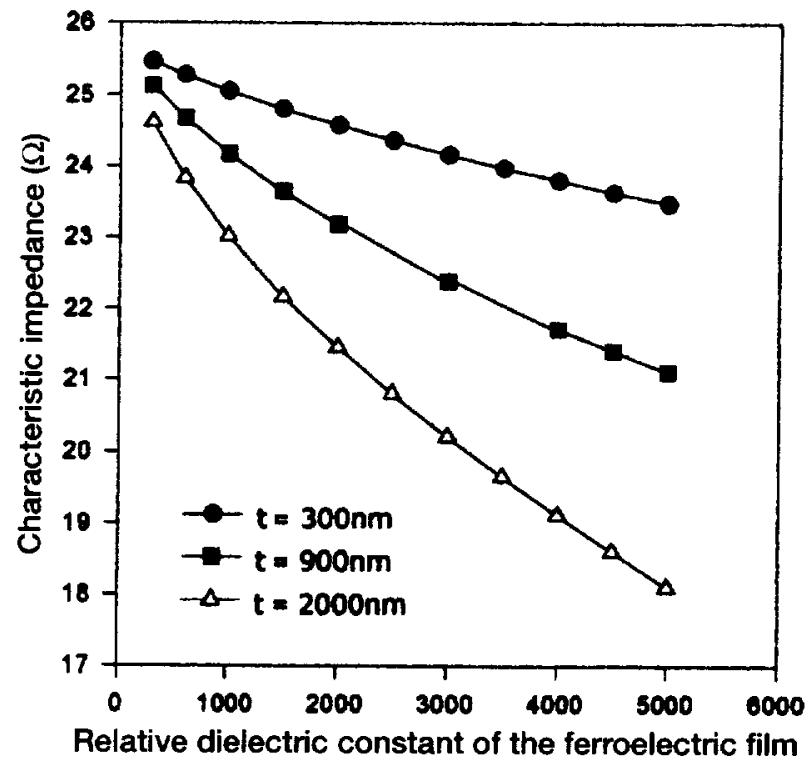

FIGURE 8 Modeled data for characteristic impedance $\left(Z_{\mathrm{o}}\right)$ of a $25 \Omega$ line versus the relative dielectric constant of the ferroelectric film $\left(\varepsilon_{\mathrm{rFE}}\right)$ for three different thicknesses of the ferroelectric film at $15 \mathrm{GHz}$ and $\tan \delta=0.01$.

Figures 9 to 12 show plots for attenuation $(\mathrm{dB} / \mathrm{cm})$ versus the thickness of the ferroelectric at $15 \mathrm{GHz}$, for a one centimeter long microstrip which in the absence of STO will exhibit a $Z_{o}=50 \Omega$. The attenuation is plotted for $\varepsilon_{\mathrm{rFE}}=300,1650$, and 3000 , with $\tan \delta$ values typical of STO and BSTO ferroelectric thin films (i.e., 0.1, 0.01, and 0.005, which represent different levels of film quality). From the aforementioned figures one can make the following observations. For a given value of $\tan \delta$, the attenuation becomes larger at higher frequencies, and for a given frequency it becomes larger as the value of $\tan \delta$ increases. Note also that for a given frequency and $\tan \delta$ value, the attenuation increases with film thickness. Because of the skin depth effect, more RF field is concentrated in the ferroelectric film at higher frequencies resulting in larger insertion loss. Also, as the value of the $\varepsilon_{\mathrm{rFE}}$ increases, the attenuation also increases. This is a consequence of mismatches resulting from the decrease in $Z_{o}$ and the increase in $\varepsilon_{\text {eff }}$ with increasing $\varepsilon_{\mathrm{r}}$. Note also that as the dielectric losses of the ferroelectric film worsen (i.e., $\tan \delta=0.1$ ) the attenuation increases dramatically, with respect to those corresponding to $\tan \delta=0.01$ and 0.005 . 


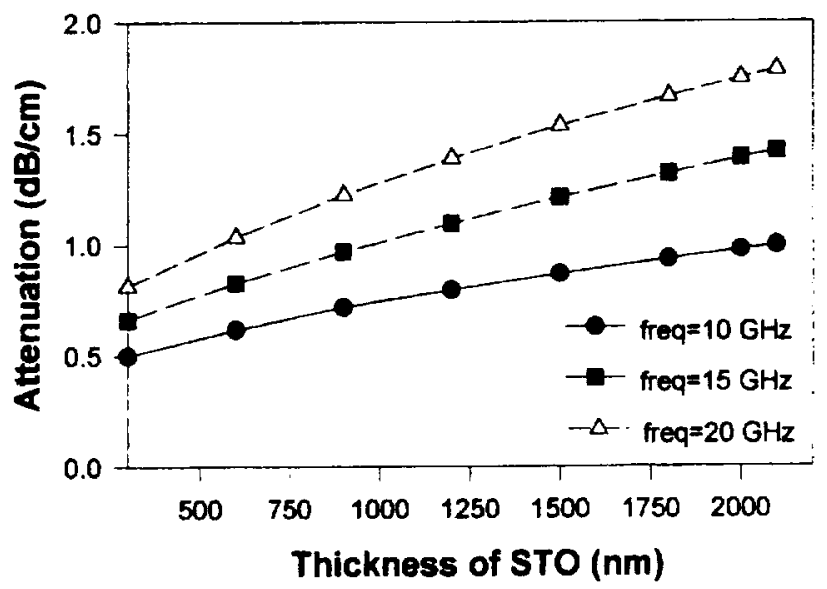

FIGURE 9 Modeled data for the attenuation versus STO thickness for a $50 \Omega$ line, $\varepsilon_{\text {rSTO }}=300, \tan \delta=0.1$, and three different frequencies.

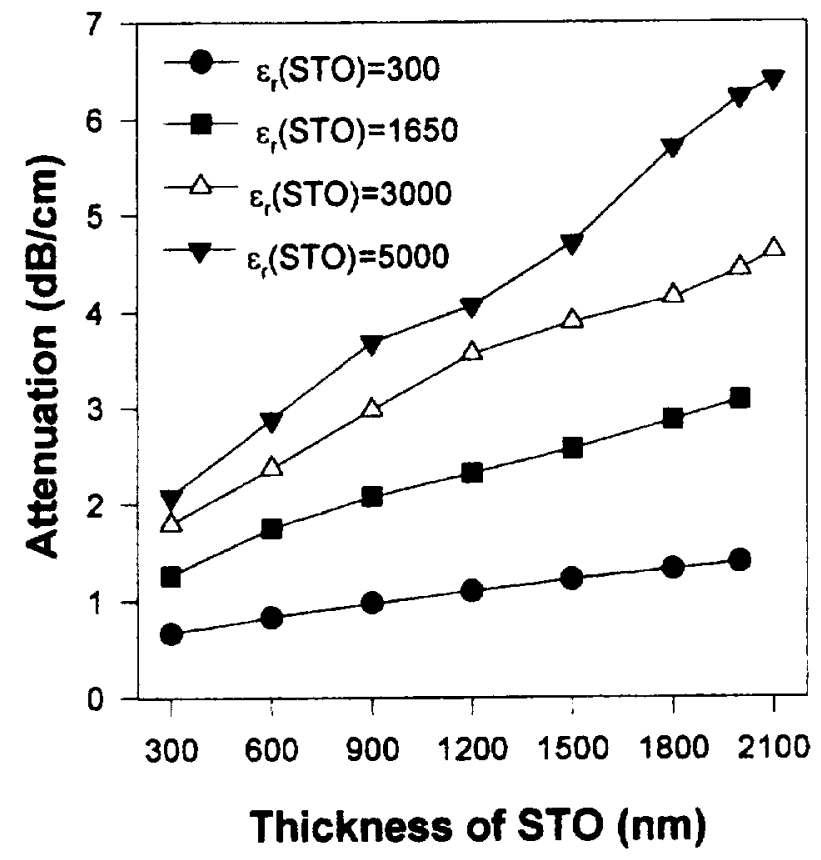

FIGURE 10 Modeled data for the attenuation versus STO thickness for a $50 \Omega$ line, $\tan \delta=0.1,15 \mathrm{GHz}$, and five different values of $\varepsilon_{\text {rSTo. }}$ 


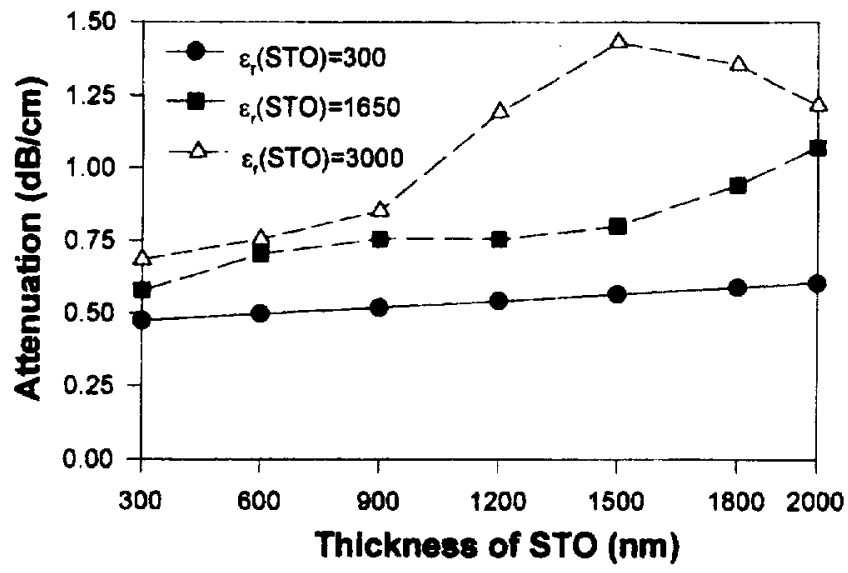

FIGURE 11 Modeled data for the attenuation versus STO thickness for a $50 \Omega$ line, $\tan \delta=0.01,15 \mathrm{GHz}$, and three different values of $\varepsilon_{\text {rsto. }}$

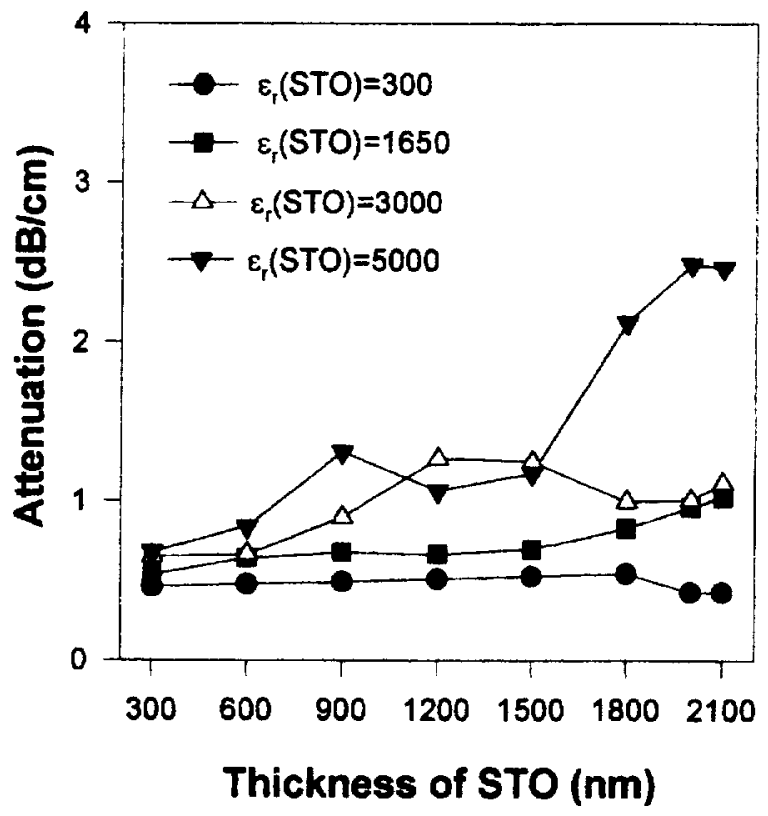

FIGURE 12 Modeled data for the attenuation versus STO thickness for a $50 \Omega$ line, $\tan \delta=0.005,15 \mathrm{GHz}$, and four different values of $\varepsilon_{\mathrm{rs}}$. 


\section{B. Experimental Results:}

\section{Correlation between modeled and measured effective dielectric constant.}

Let us consider data from ring resonators which were designed for operation at the $n=3$ resonance and fabricated with Au/STO/LAO thin film multilayered structures. ${ }^{[3]}$ These resonances satisfy the condition $\pi \mathrm{d}=3 \lambda_{\mathrm{g}}$ ( $\mathrm{d}$ is the mean diameter of the ring and $\lambda_{\mathrm{g}}$ is the guided wavelength). Knowing the resonant frequency $\left(\mathrm{f}_{3}\right)$ of the resonators, one can determine the effective dielectric constant $\left(\varepsilon_{\text {eff }}\right)$ of the resonant structure; i.e.,

$$
\varepsilon_{\text {eff }}=\left(\left[c /\left(f_{3} d\right)\right][3 / \pi]\right)^{2}=0.91189\left[c /\left(f_{3} d\right)\right]^{2}
$$

We fabricated two types of ring resonators with characteristic impedance $\left(Z_{\mathrm{o}}\right)$ of 25 and $50 \Omega$. The mean diameter (d) of these rings are $\mathrm{d}=3388 \mu \mathrm{m}$ and $3670 \mu \mathrm{m}$ for the 25 and $50 \Omega$, respectively. Therefore, the $\varepsilon_{\text {eff }}$ for the two types of rings are given by,

$\varepsilon_{\text {eff }}(25 \Omega)=7.15 \times 10^{21} / \mathrm{f}_{3}^{\frac{2}{3}}$ and $\varepsilon_{\text {eff }}(50 \Omega)=6.09 \times 10^{21} / \mathrm{f}_{3}^{2}$

Table II shows experimental data for several ring resonators, including the corresponding range of variation for $\varepsilon_{\text {eff }}$.

Consider first the $25 \Omega$ ring resonators at room temperature. The experimental and simulated values of $\varepsilon_{\text {eff }}$ for the circuits with no ferroelectric film agree within $0.4 \%$. For rings 3,5 , and 6 , the experimental room temperature $\varepsilon_{\text {eff }}$ values correspond to simulated values using $\varepsilon_{\text {rSTO }}$ values of 275 to 325 . These values agree with reported measurements of $\varepsilon_{\mathrm{rSTO}}$. Ring no. 4 has a resonant frequency corresponding to an $\varepsilon_{\mathrm{rSTO}}=150$. As the rings are cooled to $77 \mathrm{~K}$ and below, the dielectric constant of the LAO drops slightly, causing a drop of 0.33 in $\varepsilon_{\text {eff }}$ for the bare LAO ring. After adjusting for this LAO change, a comparison of experimental data and simulations for the $2 \mu \mathrm{m}$ thick STO rings indicates a range of $\varepsilon_{\mathrm{rSTO}}$ from 2900 to 1540 for biases of $10 \mathrm{~V}$ to $458 \mathrm{~V}$ for sample 5 . For sample 6 , the measured range corresponds to $\varepsilon_{\mathrm{rSTO}}$ 's of 3300 to 1700 for biases from 10 to $491 \mathrm{~V}$. The initial $10 \mathrm{~V}$ applied to the sample, causes the ring to go from over-coupled to under-coupled, greatly sharpening and shifting the resonance. The resonant frequencies obtained 
TABLE II Frequency and effective dielectric constant tuning range of $\mathrm{Au} / \mathrm{SrTiO}_{3} / \mathrm{LaAlO}_{3}$ ring resonators versus temperature and bias

\begin{tabular}{|c|c|c|c|c|c|c|}
\hline $\begin{array}{c}\begin{array}{c}\text { Sample } \\
\text { no. }\end{array} \\
\text {. }\end{array}$ & $\begin{array}{c}\text { Design and } \\
\text { STO thickness }\end{array}$ & $\begin{array}{l}\mathrm{f}_{3} \text { at room } \\
\text { temperature }\end{array}$ & $\begin{array}{l}\mathrm{T}, \\
\mathrm{K}\end{array}$ & $\begin{array}{c}\text { Maximum } \\
V_{R}, \\
V\end{array}$ & $\begin{array}{c}\mathrm{f}_{3} \text { range, } \\
\mathrm{GHz}\end{array}$ & $\varepsilon_{\text {eff }}$ range \\
\hline 1 & $\begin{array}{l}\text { Au } 50 \Omega \text { ring, } \\
300 \mathrm{~nm}\end{array}$ & 19.152 & 40 & 300 & $14.6-16.2$ & $28.57-23.21$ \\
\hline 1 & $\begin{array}{l}\text { Au } 50 \Omega \text { ring, } \\
300 \mathrm{~nm}\end{array}$ & 19.152 & 77 & 350 & $15.1-16.8$ & $26.71-21.57$ \\
\hline 2 & $\begin{array}{l}\text { Au } 25 \Omega \text { ring, } \\
\text { no STO }\end{array}$ & 20.275 & 40 & $\mathrm{Na}$ & 20.48 & 17.05 \\
\hline 2 & $\begin{array}{l}\text { Au } 25 \Omega \text { ring, } \\
\text { no STO }\end{array}$ & 20.275 & 77 & $\mathrm{Na}$ & 20.47 & 17.06 \\
\hline 3 & $\begin{array}{l}\text { Au } 25 \Omega \text { ring, } \\
300 \mathrm{~nm}\end{array}$ & 19.350 & 40 & 450 & $19.0-20.0$ & $19.81-17.88$ \\
\hline 3 & $\begin{array}{l}\text { Au } 25 \Omega \text { ring, } \\
300 \mathrm{~nm}\end{array}$ & 19.350 & 77 & 350 & $19.3-19.9$ & $19.20-18.06$ \\
\hline 4 & $\begin{array}{l}\text { Au } 25 \Omega \text { ring, } \\
1 \mu \mathrm{m}\end{array}$ & 19.762 & 52 & 250 & $17.0-18.1$ & $24.74-21.8$ \\
\hline 5 & $\begin{array}{l}\mathrm{Au} 25 \Omega \text { ring, } \\
2 \mu \mathrm{m}\end{array}$ & 19.435 & 77 & 458 & $15.75-17.64$ & $28.82-22.98$ \\
\hline 6 & $\begin{array}{l}\text { Au } 25 \Omega \text { ring, } \\
2 \mu \mathrm{m} \text { partially } \\
\text { etched }\end{array}$ & 19.420 & 77 & 491 & $15.27-17.26$ & $30.63-24.00$ \\
\hline
\end{tabular}

above $10 \mathrm{~V}$ are believed to be more accurate for this purpose. The upper dielectric constant values are close to those measured at $1 \mathrm{MHz}$ using interdigital capacitors on similar samples. These rings are not expected to be fully tuned to $\varepsilon_{\mathrm{rSTO}}=300$ under the voltages given here. The relevant electric field is that between the ring and the ground plane of the ring resonator. For samples 5 and 6 , the maximum electric fields are 1.93 and $1.80 \times 10^{4} \mathrm{~V} / \mathrm{cm}$. Using $\mathrm{Au} / \mathrm{STO} / \mathrm{LAO}$ interdigital capacitors at $1 \mathrm{MHz}$, we have found that upon applying such a field, $\varepsilon_{\mathrm{rSTO}}$ reach values near 1300 at $77 \mathrm{~K}$.

We observe that for sample 3 of Table II, which has a thinner STO film, $\varepsilon_{\text {eff }}$ of 17.88 under a ring bias of $450 \mathrm{~V}$ and at $40 \mathrm{~K}$. Note also, that the experimental value obtained for the effective dielectric constant of the same ring measured at $77 \mathrm{~K}$ under a bias of $350 \mathrm{~V}$ is 18.06 which is within $5.7 \%$ of the modeled value for $\varepsilon_{\text {rSTO }}=1000$, which is 19.092 at $20 \mathrm{GHz}$. Consider now sample 4 of Table II, which corresponds to a $1 \mu \mathrm{m} \mathrm{STO}$ thin film; it shows $\varepsilon_{\text {eff }}=21.8$ under a $250 \mathrm{~V} \mathrm{dc}$ bias and at $52 \mathrm{~K}$. For this structure, the total electric field between the ring and the 
ground plane for the above bias is approximately $1 \times 10^{4} \mathrm{~V} / \mathrm{cm}$. Using the same capacitor technique, we have found that upon applying such a field, $\varepsilon_{\text {rSTO }}$ reach values near 1700 at $50 \mathrm{~K}$. Thus, if one compares the modeled data for $\varepsilon_{\text {eff }}$ corresponding to $\varepsilon_{\text {rSTo }}=1500$ at $20 \mathrm{GHz}$ (which is the closest modeled value available) with the experimental data we observe that the modeled value of $\varepsilon_{\text {eff }}=21.327$ differs from 21.8 by $2.2 \%$ which represents an acceptable correspondence between the modeled and the experimental data. Note that in general, the modeled data agree very well with the experimental data. The major reasons for discrepancies arise from the fact that experimentally only the STO almost directly under the ring is influenced by the electric field in contrast to the simulations where it tunes everywhere. Also, there is some variation in $\varepsilon_{\mathrm{rSTO}}$ between films without any simple way to measure it at these frequencies. Discrepancies between the actual and expected thickness of the films, due primarily to fabrication tolerances, could also exist. Nevertheless, from Table II we can see that the films presented here are very tunable and of high quality. The good agreement between the modeled and experimental data discussed above demonstrate the usefulness of the modeled plot in selecting geometrical and film thickness parameters for a targeted application.

Considering the $50 \Omega$ ring (sample 1 of Table II), it shows an effective dielectric constant of 23.21 at $40 \mathrm{~K}$ and $16 \mathrm{GHz}$ under a dc bias of $300 \mathrm{~V}$. This bias translates into a field of $1.2 \times 10^{4} \mathrm{~V} / \mathrm{cm}$. At $40 \mathrm{~K}$, this bias results in an experimental $\varepsilon_{\mathrm{rSTO}}=1700$. Thus, the modeled $\varepsilon_{\text {eff }}$ corresponding to this dielectric constant $\varepsilon_{\mathrm{rSTO}}=1500$ (closest modeled data available to 1700 ) at $15 \mathrm{GHz}$ is 18.031 , which represents a $22 \%$ discrepancy. However, when we use the part of Eq. (2) corresponding to $50 \Omega$ and the $3 \lambda_{\mathrm{g}}$ frequency of resonance for this ring resonator at room temperature $(19.152 \mathrm{GHz})$ we obtain $\varepsilon_{\text {eff }}=16.6$. Reported values for $\varepsilon_{\mathrm{rSTO}}$ at room temperature falls between 275 and 325 . Thus, when comparing the experimental value with the modeled effective dielectric constant of $\varepsilon_{\mathrm{eff}}=16.356$ corresponding to $\varepsilon_{\mathrm{rSTO}}=300$, we find that they agree within $1.5 \%$. It is possible that the narrower lines have a greater discrepancy between experiment and simulation because of the larger extent of the microwave fringing fields away from the lines in regions where the dc bias is not effecting the film as strongly in actuality as it does in the model. More measurements of this type of structures at low temperature are underway. 


\section{Correlation between experimental and modeled attenuation}

Figure 13 shows the magnitude of the transmission scattering parameter $\left(\mathrm{S}_{21}\right)$ for $1 \mathrm{~cm}$ long, $50 \Omega \mathrm{Au} / \mathrm{STO} / \mathrm{LAO}$ microstripline, with a $2 \mu \mathrm{m}$ STO thin film. The data were obtained at $77 \mathrm{~K}$ in the 10 to $20 \mathrm{GHz}$ frequency range. Observe that at no bias and at $16.5 \mathrm{GHz}$, the insertion loss $\left(\mathrm{I}_{\mathrm{L}}\right)=4.68 \mathrm{~dB}$. These experimental data are not de-embedded, meaning that any contribution from the SMA launchers used for the measurement to the overall insertion loss has not been subtracted from the data. In any case, we estimate this launcher contribution to be not higher than $0.2 \mathrm{~dB} .^{[11]}$ Since no bias is applied and we are operating at $77 \mathrm{~K}$, it is reasonable to consider $\varepsilon_{\text {rSTO }}$ to be somewhere in the range of 3000 to 5000 . Figure 14 shows modeled data at $15 \mathrm{GHz}$ for a $\mathrm{Au} / \mathrm{STO} / \mathrm{LAO}$ line with a $2 \mu \mathrm{m}$ STO film for $\varepsilon_{\mathrm{rSTO}}=5000$ and $\tan \delta=0.01$, resulting in an attenuation of $2.67 \mathrm{~dB}$, which is within a factor of 2 of the measured result. When modeling for this line is done for $\tan \delta=0.05$ and 0.1 , the attenuation becomes 4.21 and $6.22 \mathrm{~dB}$, respectively. Similar data are shown in Fig. 15, for another Au/STO $(2 \mu \mathrm{m}$ thick $) / \mathrm{LAO}, 1 \mathrm{~cm}$ thru line. At $16.6 \mathrm{GHz}$ the insertion loss is $4.71 \mathrm{~dB}$ which again is consistent with the modeled data for $\tan \delta=0.05$. In both cases, the modeled data corresponding to $\tan \delta=0.05$ is within $11 \%$ of the values measured experimentally. Other sources, such as conductor loss and mismatches, may also contribute to the observed discrepancy between experimental and modeled data. Figure 16 shows a YBCO/STO $(2 \mu \mathrm{m}$ thick $) / \mathrm{LAO}$ microstrip line at $77 \mathrm{~K}$. Note that at $15 \mathrm{GHz}$ and $400 \mathrm{~V} \mathrm{dc}$, the attenuation is approximately $4 \mathrm{~dB}$, which is also consistent with $\tan \delta=0.05$.

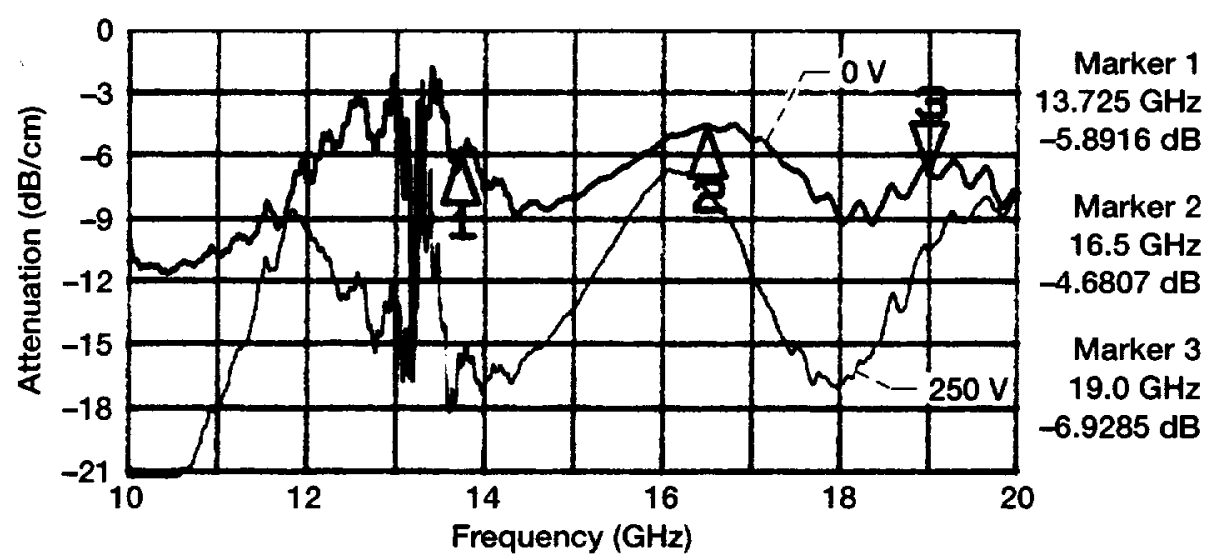

FIGURE 13 Experimental data for the attenuation versus frequency for a $1 \mathrm{~cm}$ long, $50 \Omega$ Au/STO/LAO microstripline with a $2 \mu \mathrm{m}$ thick STO film at $77 \mathrm{~K}$. 


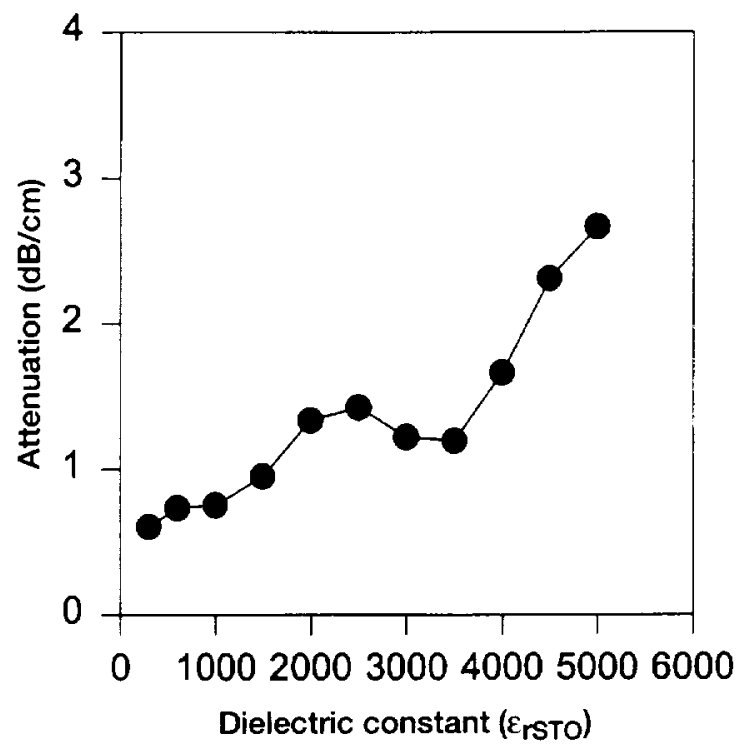

FIGURE 14 Modeled data at $15 \mathrm{GHz}$ for the attenuation of a Au/STO/LAO line with a $2 \mu \mathrm{m}$ STO film versus $\varepsilon_{\text {rSTO }}$ for $\tan \delta=0.01$.

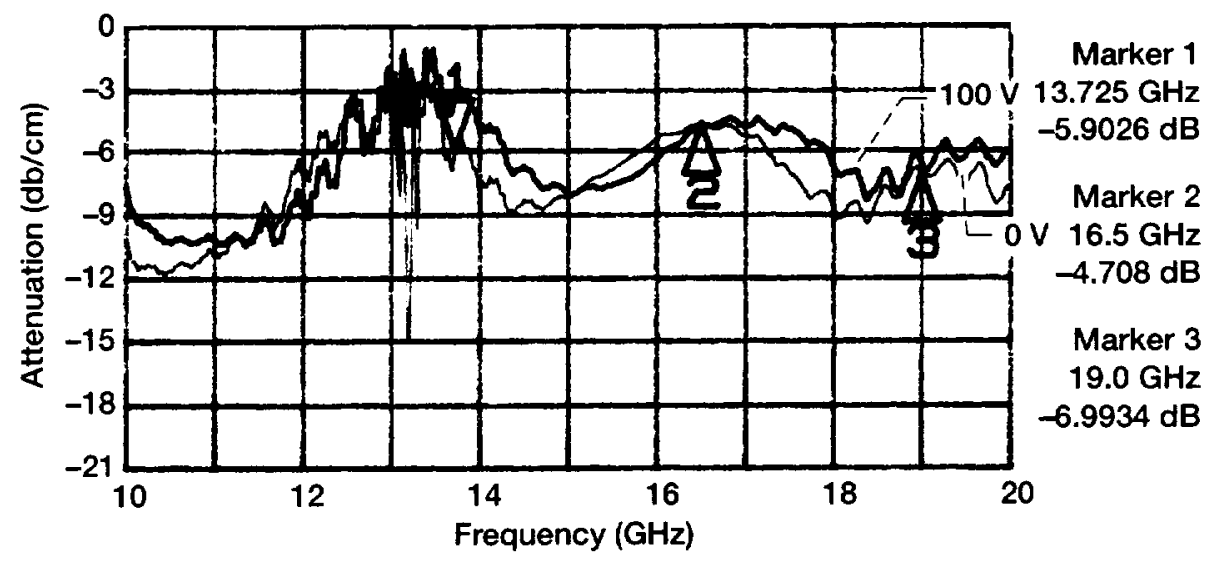

FIGURE 15 Experimental data for the attenuation versus frequency for a $1 \mathrm{~cm}$ long, $50 \Omega$ Au/STO/LAO microstripline with a $2 \mu \mathrm{m}$ thick STO film at $77 \mathrm{~K}$ (not the same sample as in Fig. 13). 


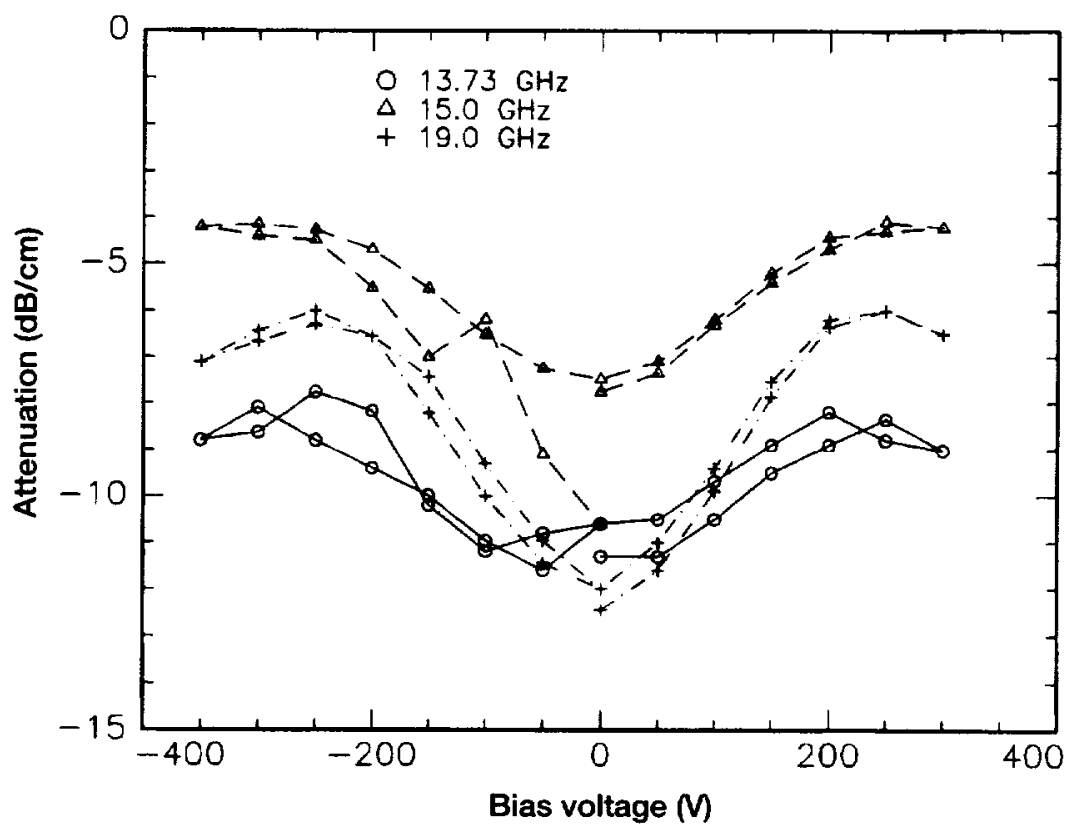

FIGURE 16 Experimental data for the attenuation versus frequency for a $1 \mathrm{~cm}$ long, $50 \Omega \mathrm{YBCO} / \mathrm{STO} / \mathrm{LAO}$ micrsotripline with a $2 \mu \mathrm{m}$ thick STO film at $77 \mathrm{~K}$.

These examples also show that the modeled data are helpful in assessing the expected losses of a thin film ferroelectric-based tunable circuit.

\section{Biasing Effects:}

Before finishing this manuscript we would like to discuss briefly the biasing effects on microstrip line-based ferroelectric circuits that are more complicated than a single microstrip. When several adjacent microstrips are employed, the dc biasing effects not only each line but also the coupling between lines. One can bias different sections of the circuit differently in order to optimize each section and/or the coupling between sections. The effect of the applied dc electric field (primarily responsible for tunability in these planar components) on the parameters such as the insertion loss, center frequency, the return loss, and the bandwidth of the microstrip resonators and bandpass filters have been studied experimentally. ${ }^{[3]}$ In the resonators, choosing the right biasing scheme, one can optimize the coupling and sharpen the resonance while maintaining large tunabilities. ${ }^{[3]}$ In the bandpass filters, one can reduce the insertion loss of the pass-band, or maintain the passband relatively unchanged over a tunable frequency range depending on the biasing scheme employed. ${ }^{[12]}$ Three different biasing schemes have been studied to date: (1) unipolar 
bias (UPB) where alternate nodes were biased positive, and ground, (2) partial bipolar bias (PBB) where input and output lines were grounded, and the resonator sections biased positive and negative alternatively, (3) Full bipolar bias (FBB) where alternate sections (including the input and output lines) were biased positive and negative. For a schematic representation of the above biasing schemes we would like to refer the reader to Fig. 1 of Ref. 12. It is important to note that the effective dielectric constant of the microstrip structure depends upon the electric field between the biased microstrip lines as well as the perpendicular field between the top conductor and the ground plane. In general, the FBB configuration gives the largest frequency tunability due to higher electric fields that can be applied in this configuration, and the PBB gave the lowest insertion loss in the passband in the ferroelectric tunable microstrip filters. Large tunability does not necessarily give the lowest insertion loss for the filters. An important finding was that the percentage tunability remained essentially the same for a specific applied electric field, irrespective of the biasing scheme employed. ${ }^{[12]}$

\section{CONCLUSIONS}

A study on the correlation between the material properties and relevant circuit parameters for ferroelectric thin film-based tunable microwave components has been presented. The study considered structures based on microstrip line configuration at frequencies from 10 to $20 \mathrm{GHz}$. Modeled results of circuit parameters such as the characteristic impedance, effective dielectric constant, and the attenuation in terms of ferroelectric film's dielectric properties and thickness were presented. It was observed that for a given substrate and ferroelectric thickness, smaller line width results in higher tunability of the characteristic impedance and effective dielectric constant. This implies that one can choose higher characteristic impedance for obtaining larger frequency tunability as it is directly related to the percentage change in $Z_{o}$ and $\varepsilon_{\text {eff }}$. The reliability of the modeled data was tested against experimental data corresponding to two specific types of components: ring resonators and microstrip transmission lines. In general, the modeled value for the effective dielectric constant agreed reasonably well (i.e., within less than 6\%) with those measured experimentally. On the other hand, the deviation between modeled and experimental data for the attenuation was of the order of $10 \%$. 
This discrepancy may be attributed to other sources of losses present in real circuits such as impedance mismatches originating from temperature or bias-induced variations of the ferroelectric's dielectric constant, and conductor losses, which becomes more relevant at high frequencies. In reality the problem is more complicated since it is known that there are spatial variations of the dielectric constant of the ferroelectric film, either intrinsic or bias induced, which were not taken into account in this study. Nevertheless, the information presented here should facilitate selection of appropriate electrical and geometrical parameters for practical applications of ferroelectric tunable microwave components and circuits.

\section{References}

[1.] D.M. Dalbert, R.E. Stauber, J.C. Price, C.T. Rogers, and D. Galt, Appl. Phys. Lett., 72, 507 (1998).

[2.] H-D. Wu and F.S. Barnes, Integrated Ferroelectrics 22, 291(1998).

[3.] F.W. Van Keuls, R.R. Romanofsky, D.Y. Bohman, and F.A. Miranda, Integrated Ferroelectrics 22, 883 (1998).

[4.] G. Subramanyam, F.W. Van Keuls, and F.A. Miranda, IEEE MTT-S Digest, 1011 (1998).

[5.] R. R. Romanofsky, F. W. Van Keuls, and F. A. Miranda, Journal de Physique IV 8, 171 (1998).

[6.] F.W. Van Keuls, R.R. Romanofsky, and F.A. Miranda, Integrated Ferroelectrics 22, 893 (1998).

[7.] J. Synowczynski, L.C. Sengupta, and L.H. Chu, Integrated Ferroelectrics, 22, 861 (1998).

[8.] F.A. Miranda, C.H. Mueller, C.D. Cubbage, K.B. Bhasin, R.K. Singh, and S.D. Harkness, IEEE Trans. on Appl. Supercond. 5, 3191 (1995).

[9.] Sonnet Software, Inc., Liverpool, NY, CA.; Zeland Software, Inc., Fremont, CA.

[10.] R.R. Romanofsky, "500 V X/K-Band Bias Tee" (unpublished).

[11.] M. Mejia, A.S. Creason, S.S. Toncich, B.T. Ebihara, and F.A. Miranda, Advances in Cryogenic Engineering, 41, 1731 (1996).

[12.] G. Subramanyam, F.W. Van Keuls, F.A. Miranda, C.L. Canedy, S. Aggarwal, T. Venkatesan, and R. Ramesh, Correlation of Electric Field and Critical Design Parameters for Ferroelectric Tunable Microwave Filters. Presented at the $11^{\text {th }}$ International Symposium on Integrated Ferroelectrics, March 7-10, 1999, Colorado Springs, $\mathrm{CO}$. 
, 
Public reporting burden for this collection of information is estimated to average 1 hour per response, including the time for reviewing instructions, searching existing data sources, gathering and maintaining the data needed, and completing and reviewing the collection of information. Send comments regarding this burden estimate of any other aspect of this collection of information, including suggestions for reducing this burden, to Washington Headquarters Services, Directorate for Information Operations and Reports, 1215 Jefferson Davis Highway, Sutte 1204, Artington, VA 22202-4302, and to the Oftice of Management and Budget. Paperwork Reduction Project (0704-0188), Washington, DC 20503.

\begin{tabular}{l|l|l} 
1. AGENCY USE ONLY (Leave blank) & 2. REPORT DATE & 3. REPORT TYPE AND DATES COVERED
\end{tabular}

4. TITLE AND SUBTITLE

April 2000

Technical Memorandum

Correlation Between Material Properties of Ferroelectric Thin Films and Design Parameters for Microwave Device Applications: Modeling Examples and Experimental Verification

6. AUTHOR(S)

Félix A. Miranda, Fred W. Van Keuls, Guru Subramanyam, Carl H. Mueller,

Robert R. Romanofsky, and Gerardo Rosado

7. PERFORMING ORGANIZATION NAME(S) AND ADDRESS(ES)

National Aeronautics and Space Administration

John H. Glenn Research Center at Lewis Field

Cleveland, Ohio 44135-3191

8. PERFORMING ORGANIZATION REPORT NUMBER

E-11586

9. SPONSORING/MONITORING AGENCY NAME(S) AND ADDRESS(ES)

National Aeronautics and Space Administration

Washington, DC 20546-0001

10. SPONSORING/MONITORING AGENCY REPORT NUMBER

NASA TM-2000-208876

\section{SUPPLEMENTARY NOTES}

Prepared for the 11 th International Symposium on Integrated Ferroelectrics cosponsored by the Gordon and Breach Science Publishers, and the Univeristy of Colorado, Colorado Springs, Colorado, March 7-10, 1999. Félix A. Miranda, Fred W. Van Keuls, Carl H. Mueller and Robert R. Romanofsky, NASA Glenn Research Center; Guru Subramanyam, University of Dayton, 300 College Park, Dayton, Ohio 45469: Gerardo Rosado. University of Puerto Rico. Humacao. Puerto Rico 0079l. Responsible person, Félix A. Miranda, organization code $5620,(216) 433-6589$.

12a. DISTRIBUTION/AVAILABILITY STATEMENT 12b. DISTRIBUTION CODE

Unclassified - Unlimited

Subject Category: 33

Distribution: Nonstandard

This publication is available from the NASA Center for AeroSpace Information. (301) 621-0390.

13. ABSTRACT (Maximum 200 words)

The application of thin ferroelectric films for frequency and phase agile components is the topic of interest of many research groups worldwide. Consequently, proof-of-concepts (POC) of different tunable microwave components using either (HTS, metal)/ferroelectric thin film/dielectric heterostructures or (thick, thin) film "flip-chip" technology have been reported. Either as ferroelectric thin film characterization tools or from the point of view of circuit implementation approach, both configurations have their respective advantages and limitations. However, we believe that because of the progress made so far using the heterostructure (i.e., multilayer) approach, and due to its intrinsic features such as planar configuration and monolithic integration, a study on the correlation of circuit geometry aspects and ferroelectric material properties could accelerate the insertion of this technology into working systems. In this paper, we will discuss our study performed on circuits based on microstrip lines at frequencies above $10 \mathrm{GHz}$, where the multilayer configuration offers greater ease of insertion due to circuit's size reduction. Modeled results of relevant circuit parameters such as the characteristic impedance, effective dielectric constant, and attenuation as a function of ferroelectric film's dielectric constant, tan $\delta$, and thickness, will be presented for $\mathrm{SrTiO}_{3}$ and $\mathrm{Ba}_{\mathrm{x}} \mathrm{Sr}_{1-\mathrm{x}} \mathrm{TiO}_{3}$ ferroelectric films. A comparison between the modeled and experimental data for some of these parameters will be presented.

14. SUBJECT TERMS

Ferroelectric films: Tunable microwave components; Microstripline configuration: Characteristic impedance; Effective dielectric constant: Attenuation; $\mathrm{SrTiO}_{3} ; \mathrm{Ba}_{\mathrm{x}} \mathrm{Sr}_{1-\mathrm{x}} \mathrm{TiO}_{3} ; \mathrm{LaAlO}_{3} ; 10-20 \mathrm{GHz}$

\begin{tabular}{|c|c|c|}
\hline $\begin{array}{c}\text { 17. SECURITY CLASSIFICATION } \\
\text { OF REPORT } \\
\text { Unclassified }\end{array}$ & $\begin{array}{c}\text { 18. SECURITY CLASSIFICATION } \\
\text { OF THIS PAGE } \\
\text { Unclassified }\end{array}$ & $\begin{array}{c}\text { 19. SECURITY CLASSIFICATION } \\
\text { OF ABSTRACT } \\
\text { Unclassified }\end{array}$ \\
\hline
\end{tabular}

NSN 7540-01-280-5500

\begin{tabular}{|} 
15. NUMBER OF PAGES \\
26 \\
\hline $\begin{array}{c}\text { 16. PRICE CODE } \\
\text { A03 }\end{array}$ \\
20. LIMITATION OF ABSTRACT \\
\end{tabular}

